University of St. Thomas, Minnesota

UST Research Online

2013

\title{
A quasi-experimental assessment of interactive student response systems on student confidence, effort, and course performance
}

\author{
Lawrence Chui \\ University of St. Thomas, Minnesota, lawrence.chui@stthomas.edu \\ Kasey Martin \\ Texas State University - San Marcos, kasey.martin@txstate.edu \\ Byron Pike \\ Minnesota State University - Mankato, byron.pike@mnsu.edu
}

Follow this and additional works at: https://ir.stthomas.edu/ocbacctpub

Part of the Accounting Commons

This Article is brought to you for free and open access by the Accounting at UST Research Online. It has been accepted for inclusion in Accounting Faculty Publications by an authorized administrator of UST Research Online. For more information, please contact asle4660@stthomas.edu. 
Main article

\title{
A quasi-experimental assessment of interactive student response systems on student confidence, effort, and course performance
}

\author{
Lawrence Chui $^{\mathrm{a}, *}$, Kasey Martin ${ }^{\mathrm{b}, 1}$, Byron Pike ${ }^{\mathrm{c}, 2}$ \\ a Department of Accounting, Opus College of Business, University of St. Thomas, St. Paul, MN 55105, United States \\ ${ }^{\mathrm{b}}$ Department of Accounting, McCoy College of Business Administration, Texas State University - San Marcos, San Marcos, TX 78666 , \\ United States \\ ${ }^{\mathrm{c}}$ Department of Accounting and Business Law, College of Business, Minnesota State University, Mankato, Mankato, MN 56001, \\ United States
}

\section{A R T I C L E I N F O}

\section{Article history:}

Available online 8 February 2013

\section{Keywords:}

Interactive student response system (SRS)

Clickers

Course performance

Interactive classroom tools

\section{A B S T R A C T}

The interactive student response system (SRS), commonly referred to as 'clickers,' is an alternative learning method that has the potential to improve student course (i.e., quiz/examination) performance. Prior SRS studies both within accounting and other academic disciplines have found conflicting results as to its influence on student course performance. This quasi-experimental study re-examines the relationship between the use of an SRS and course performance. We also investigate how using SRS influences student confidence and time spent studying outside of class. Unlike prior SRS related studies, we tested both our SRS class and our control class (with no SRS) in the same academic semester with the same instructor to provide a higher degree of experimental control. Through doing so, we compared the benefit of immediate feedback achieved by SRS to the delayed feedback of traditional assessment formats. Higher in-class performance on multiple-choice quiz items was found for students using SRS versus those who did not use SRS; however, no significant differences in examination performance or overall course performance were noted between the two groups. Students using SRS reported being more confident in their abilities and spent less time preparing for the course outside of class, while maintaining similar overall course performance when compared to

\footnotetext{
* Corresponding author. Tel.: +1 651962 5442; fax: +1 6519625093.

E-mail addresses: lawrence.chui@stthomas.edu (L. Chui), kasey.martin@txstate.edu (K. Martin), byron.pike@mnsu.edu (B. Pike).

1 Tel.: +1 512245 3906; fax: +1 5122457973 .

2 Tel.: +1 507389 6909; fax: +1 5073895497 .
} 
those who did not use the SRS. We conclude our study by providing areas of meaningful future research related to the use of SRS.

(c) 2013 Elsevier Ltd. All rights reserved.

\section{Introduction}

Educators and researchers have devoted extensive efforts to achieve a better understanding of the educational process and improve student performance. Advances in technology provide new and innovative means of potentially improving the course performance of students. Consistent with prior literature, we define course performance as the scores attained by students during the assessment phases of a class (Caldwell, 2007; Kay \& LeSage, 2009; MacArthur \& Jones, 2008). The interactive student response system (SRS) represents an advanced technique for assessing student course performance. In its most generic form, SRS is a polling device that gives instructors the ability to instantaneously gather student responses to one or a series of multiple-choice/open-ended questions related to the course material. ${ }^{3}$ SRS responses provide instructors with immediate feedback regarding student understanding of the material presented. The primary purpose of SRS is to provide educators with a simple way to receive regular feedback on what, how much, and how well their students comprehend the course material (Angelo, 1991; Cottell, 1991; Eisenbach, Golich, \& Curry, 1998). SRS also allows instructors to immediately alter class content to emphasize topics or subject matter the students do not fully understand. Moreover, students are provided with immediate feedback regarding their own comprehension of the course material. While SRS technology has the potential to improve the educational process, little is known about how SRS affects student course performance as measured by in-class quizzes and examinations.

Four recent studies (Carnaghan \& Webb, 2007; Edmonds \& Edmonds, 2008; Mula \& Kavanagh, 2009; Segovia, 2008) examined the impact of SRS on course performance (proxied by exam scores) in introductory accounting courses. Carnaghan and Webb (2007) and Mula and Kavanagh (2009) found SRS did not improve course performance. In contrast, Edmonds and Edmonds (2008) and Segovia (2008) claimed SRS significantly improved student performance. The research on the use of clickers in the classroom in other academic disciplines has generated similar mixed results of either a positive or no influence on course performance, as measured by exam scores (Caldwell, 2007; Kay \& LeSage, 2009; MacArthur \& Jones, 2008). These conflicting findings raise concerns about the benefit of SRS on course performance in higher education, and specifically in accounting. The diversity in research findings may stem from research designs in the extant literature failing to compare SRS environments to appropriate non-SRS environments (Fies \& Marshall, 2006).

The purpose of this study is to further assess the relationship between SRS and student course performance by comparing in-class quiz and exam results from students using clickers to those subjected to a more traditional classroom environment (i.e., without clickers). In addition, we examine the influence of the timing of feedback, which can be accelerated with SRS, on student confidence in quiz/exam performance and the amount of effort exerted outside of class.

We designed a quasi-experiment to examine the relationship between SRSs and student course performance. One class used SRS and another class did not use SRS. We found students using SRSs scored significantly higher on in-class quizzes than those who did not use SRSs. Although overall course performance was no different between those using SRS and those not using SRS, the SRS group reported a higher level of confidence and less time spent studying outside of class. We believe our results have the potential to provide insight into how accounting educators may integrate SRSs in their classrooms to enhance student course performance and their learning experience.

We contribute to the accounting literature by providing further evidence on the relationship between SRS and student performance. Moreover, we go beyond the mere examination of the potential gain in course performance from using clickers and investigate how the individual characteristics of

\footnotetext{
${ }^{3}$ Using an SRS, students can submit their responses via a handheld clicker, laptop, or smart-phone. The instructor's receiving device, either web-based or wireless, instantaneously captures the students' responses. After polling is closed for each question, the instructor has the option to display the distribution of students' responses and indicate the correct answer.
} 
confidence and effort are influenced by the use of SRS. In addition, unlike prior SRS related studies, we tested both our SRS class and our control class (with no SRS) in the same academic semester, with the same instructor, and the same course content, thus providing a higher degree of experimental control. Finally, and most importantly, our study contributes to the literature by comparing the SRS technology and its benefit of immediate feedback versus the control group that received delayed feedback by using quizzes administered at the end of a class period and reviewed during the next class.

In the following sections, we discuss our theory and hypothesis development, our research approach, and the empirical results of our study. We conclude by discussing the major findings, implications, limitations, and potential areas for future research.

\section{Background}

Conventionally graded evaluative instruments, such as written assignments, multiple-choice questions, short-answer questions, and essay-oriented examinations and quizzes, have been used to measure student course performance (Brown, Bull, \& Pendlebury, 1997; Cottell \& Harwood, 1998). However, educators have criticized these methods for their inability to both properly assess and improve student performance (Angelo, 1991; Bell, 2003; Grygoryev \& Karapetrovic, 2005; Horsburgh, 1999). Angelo (1991) developed a series of small-scale Classroom Assessment Techniques (CATs) to help educators better determine whether students are learning. Unlike conventionally graded evaluative instruments, CATs include questionnaires and short exercises such as classroom assessment quality circles, electronic mail feedback, concept maps, applications cards, and course-embedded assessments (Ammons \& Mills, 2005; Angelo \& Cross, 1993). ${ }^{4}$ Angelo (1991) argues that CATs supplement traditional assessment tools by allowing educators to find out how well their students comprehend the course material. The earlier educators discover a learning issue among their students the less negative impact there is on course performance (Grygoryev \& Karapetrovic, 2005).

An innovative application of CATs includes the interactive student response system (SRS). More versatile than many of the CATs, instructors can use SRS to gather instant, real-time student feedback, track class attendance and participation frequency, and record in-class quiz scores. ${ }^{5}$ The core advantage of SRS is that it provides a dual form of feedback. For students, SRS gives them an opportunity to reflect on their comprehension of the course material and identify areas that would require additional efforts to enhance their mastery of the subject matter. For instructors, SRS provides a mechanism for obtaining an immediate and anonymous understanding of how well their students comprehend the presented material. Based on these responses, instructors can immediately decide either to revisit the previously covered material in more detail or to move onto presenting another topic.

While the use of SRS appears to have the potential to improve student course performance, little empirical evidence supports such a claim. Within accounting, researchers have explored the effects of SRS on student course performance in introductory accounting classes. For example, Carnaghan and Webb (2007), Edmonds and Edmonds (2008), Segovia (2008), and Mula and Kavanagh (2009) examined how the use of an SRS improves accounting student examination performance. However, the findings of these studies, taken as a whole, were inconclusive and deserve further investigation.

Carnaghan and Webb (2007) hypothesized that students who use an SRS will outperform those without the response system over the same learning material. They also postulated that students with

\footnotetext{
${ }^{4}$ Classroom assessment quality circles provide a means for faculty to regularly collect thoughtful responses from students on their assessments. They also offer students a structured and positive way to become more actively involved in their classroom learning. Concept maps provide teachers with an observable and assessable record of the students' conceptual schemata. They allow the teacher to assess the adequacy of student understanding of relevant conceptual relations. Application cards give instructors an opportunity to know how well students understand the possible applications of what they have learned (Angelo, 1991; Angelo \& Cross, 1993). Course-embedded assessment is the collection of data about what and how students are learning via the use of classroom activities. It provides prompt feedback of learning information to both teachers and students. Assessment may be embedded written assignments, case studies, presentations, or surveys that ask students to self-report on their learning experiences (Ammons \& Mills, 2005).

${ }^{5}$ Instructors will need to take caution when using SRS as a means to monitor student class attendance. It is possible that students may use another student's SRS to report attendance for a friend who is in fact absent. We recommend instructors consider supplementing SRS attendance reports with other means of reporting such as a seating chart or sign-in sheet.
} 
an SRS will be more engaged during class than those who are without the response system. ${ }^{6}$ However, Carnaghan and Webb (2007) found that accounting students who used SRS performed no differently on course examinations than those who did not use the student response system. They also found that students with an SRS were less engaged during class than those without the response system. Thus, Carnaghan and Webb (2007) concluded SRS is not an effective tool for improving student course performance. Similarly, Mula and Kavanagh (2009) examined whether the use of an SRS led students to perceive a greater understanding of the course material in their first accounting class. They also examined whether SRS helps students improve their scores on classroom assessments. Mula and Kavanagh (2009) found that although student perceptions of their understanding of the course material were greater in the SRS group, there were no significant differences in the assessment scores between the SRS group and the non-SRS group.

Edmonds and Edmonds (2008) hypothesized that accounting students with an SRS would score higher on examinations than those who were without the response system. ${ }^{7}$ In contrast to the previous studies, they found students who used an SRS performed 3.15 percentage points (based on the student's test scores on three examinations out of a possible 93 points) better on average than those who did not use the response system. Consistent with the results of Edmonds and Edmonds' (2008), Segovia (2008) also found evidence to support the existence of a positive relationship between the use of SRS and student examination scores.

Research in other business and academic disciplines on the implementation of clickers in the classroom has yielded similar mixed results. Students perceive the technology to be beneficial and feel that it has a positive influence on their learning experiences but, despite the perceived benefit, findings are mixed as to whether an SRS, such as clickers, indeed helps students achieve better performance in the course (Caldwell, 2007; Kay \& LeSage, 2009; MacArthur \& Jones, 2008). Thus, the influence of SRS on accounting student course performance in the context of in-class quizzes and exams scores is unclear.

We believe that the conflicting findings in the extant literature are attributable to the following factors. First, many of the SRS studies to date were either conducted across multiple semesters or were done by splitting a single class into different (with or without SRS) treatment groups. These designs could inadvertently lead to findings that were confounded either by differing factors across semesters or by a demand effect resulting from the availability of technology that was not made available to the entire class at the same time. ${ }^{8}$ Second, and of greater importance, none of these studies dealt directly with the intended and core advantage of SRS. SRS gives both students and instructors instantaneous feedback on student course performance during in-class activities such as quizzes. A close alternative to SRS without instantaneous feedback is the use of a multiple-choice quiz administered at the end of the class period. Students generally do not receive feedback or have a discussion regarding the quiz until their instructor returns the quiz during the following class period. We believe that it is critical to compare and contrast the intended benefit of an SRS with traditional assessment techniques within accounting in order to better assess the relationship between SRS and student course performance. To date, this important comparison has not been empirically examined in the literature. For instance, within accounting, Carnaghan and Webb (2007), Mula and Kavanagh (2009), and Segovia (2008) contrasted SRS responses with verbal responses to the same questions, with no course points assigned to responses. Furthermore, Edmonds and Edmonds (2008) compared SRS to the random collection of handwritten responses to the same questions for bonus points. Thus, it remains unknown as to whether the instantaneous feedback and content revision that is possible with the use of SRS results in learning gains which outperform learning gains obtained with the delayed feedback model used in traditional accounting courses.

\footnotetext{
${ }^{6}$ Carnaghan and Webb (2007) measured student engagement using student participation frequency. They used a subjective means in collecting student participation. Specifically, they used student oral interactions with the instructor (either by asking or answering questions in class) as a means to measure student participation frequency.

${ }^{7}$ Edmonds and Edmonds (2008) believed that SRS would increase student exam performance based on the belief that SRS satisfies several of the active-learning characteristics stated by Bonwell and Eison (1991).

${ }^{8}$ According to Kirk (1968), demand effect represents the unintended consequence when the experimental procedure or environment leads research participants to make inferences about the purpose of the experiment and to respond in accordance to the perceived purpose.
} 


\section{Hypothesis development}

\subsection{In-class performance}

Prior SRS studies in accounting have only contrasted classes using clickers to informal responses from a control group without access to the clicker device. As such, no study to date in accounting has compared responses to lecture questions from a clicker class to that of a non-clicker class where more traditional assessment techniques are employed. Empirical evidence from educational studies indicates student performance on tests/quizzes is affected by the timing and frequency of the performance evaluations. By breaking the course material into smaller sections or chunks, which is possible with an SRS, instructors are able to increase the frequency of their classroom evaluation questions and consequently help improve their student scores on these tests/quizzes (Bangert-Drowns, Kulik, Kulik, \& Morgan, 1991). This hypothesized better performance is the result of the new knowledge remaining in the students' working memories and a reduction in cognitive loads compared to less frequent and longer examinations (Mory, 1996, 2003). Because the use of an SRS allows instructors to evaluate their students more regularly compared to a traditional technique that typically can only be administered once per class period, we anticipate students using an SRS will have better in-class assessment performance than those who are evaluated without the benefit of an SRS. Thus, we hypothesize (all hypotheses in alternative form):

H1. Students with SRS will perform better on in-class quizzes than those without the SRS.

\subsection{Student confidence, effort, and course performance}

Accounting studies examining the implementation of an SRS have focused primarily on student exam scores as a proxy for course performance. Thus, the extant literature has only looked at the output performance of accounting students who possess the SRS. We attempt to go beyond examining the possible output or performance benefit from using clickers in the classroom to understanding how such a technology influences individual characteristics that influence course performance.

Having the current information or knowledge fresh and easily accessible in one's working memory, which is possible with SRS, has the likely benefit of better immediate evaluation performance (H1). However, there may be some implications on student in-class performance when assessing students using a small number of questions dispersed throughout the lecture and by providing students with immediate feedback. In particular, student confidence levels in their mastery of the material and the amount of effort exerted toward the course could be affected.

Student responses, coupled with the correct answers, provide a self-monitoring mechanism for determining whether an additional amount of effort is required to learn the material. Specifically, if students are positive in their responses to a particular question and find out that they selected the correct answer, the supplied feedback would provide a signal to them that they adequately comprehend a particular topic. On the contrary, if high or moderate certainty towards a question is paired with an incorrect response, students receive a clear indication that they have yet to master the course content and could feel compelled to subsequently invest more effort in learning the material. Along the same lines if students are unsure regarding the correct answer to a question, regardless of whether they answer it correctly, they will likely determine that more effort is necessary since getting the solution correct would be a guess and getting it incorrect indicates a lack of comprehension (Renner \& Renner, 2001; Webb, Stock, \& McCarthy, 1994). The use of an SRS should result in better in-class performance and we predict this better performance will translate into greater confidence regarding the students' comprehension of the course material when compared to those without the SRS (Bojinova \& Oigara, 2011). However, the consequence of this better performance and elevated confidence is that students may exert less effort outside of class towards the course since they believe they already comprehend the material based on the periodic in-class assessments. Alternatively, less frequent and longer inclass quizzes, utilized without the aid of an SRS, would result in lower scores and less confidence among the students about their mastery of the subject matter when compared to those using an 
SRS. Consequently, we expect non-SRS students to exert more effort outside of class towards the course. Furthermore, the overall result is that student overall course performance is anticipated to be the same regardless of whether they have access to the SRS, as the students who do not adequately comprehend the concepts during class will exert more time outside of class to achieve the same level of performance (Renner \& Renner, 2001; Webb et al., 1994). Thus, we hypothesize the following:

H2. Students with an SRS will be more confident in their understanding of the course content than those without an SRS.

H3. Students with an SRS will exert less effort outside of class towards the course than those without an SRS.

H4. Overall student course performance will not differ between those with an SRS versus those without an SRS.

\section{Experimental design}

We conducted a $2 \times 1$ quasi-experiment. ${ }^{9}$ The independent variable is the use of an SRS. Consistent with prior literature, our dependent variables are defined as student scores on in-class quizzes, examinations, and total course points. We also collected student expectations of their final course grades as proxies for their confidence. Prior educational studies have used this metric (Clayson, 2005; Eason, Marcis, Burney, \& Boyles, 2009; Nowell \& Alston, 2007). Finally, we used student self-reported time spent on studying for the course per week and their attendance records as proxies for their efforts expended on the course. ${ }^{10}$ The amount of study time is widely used in the educational literature as a proxy for student effort (Fogarty \& Goldwater, 2010; Halabi, Touvinen, \& Farley, 2005; Parry, 1990). In addition, student attendance records provide us with an added independent measure of student effort. We performed our quasi-experiment in two undergraduate principle of accounting classes during the same semester. ${ }^{11}$ To maintain a high degree of internal validity, the same instructor taught both classes. ${ }^{12}$ All class materials, quizzes, and examinations were identical in both of these classes. The only differences were that the students who enrolled in one of the classes used the SRS while the students in the other course did not, and that one class was a day section and one a night section. Students in both classes were required to take 10 quizzes (comprising $17 \%$ of the course grade), three examinations (50\% of course grade), and a comprehensive final examination (33\% of course grade).

Students in the SRS group used an interactive response device to answer their quiz questions during class time as the lecture progressed..$^{13}$ A series of quiz questions were administered multiple times during each lecture after a presented topic. Results from the questions were immediately available to the instructor and the students. Moreover, those results were discussed prior to moving onto other material. Students in the non-SRS group, on the other hand, were given the same quiz questions at the end of the class time. Instead of using an interactive response device, they completed the quizzes manually. The instructor graded the quizzes and reviewed the quiz results at the beginning of the next class period to clarify the questions answered incorrectly by a large percentage of students.

\footnotetext{
${ }^{9}$ Prior to administering the accounting courses, we obtained approval from the participating university's Institutional Review Board (IRB) for the experiment and survey material.

10 After taking the final exam but before grades were released students were asked to report their expected final course grade and time per week spent on studying for the course.

${ }^{11}$ All prior SRS accounting studies also used introductory courses. However, we are the first to administer the experiment, both treatment and control, within the same semester. The afternoon class started at 2:00 pm and the evening class started at 6:00 pm, each meeting twice a week for an hour and half per class.

12 The instructor who taught both classes is one of the coauthors of this study.

13 Students in both the non-SRS and SRS class were given the identical quiz questions. We randomized the order of the answer choices as a means to minimize potential information sharing among students between sessions. Also, the instructor manually took attendance using a seating chart in the SRS class and compared this to the attendance taken electronically. No differences were found. We understand that cheating is a concern when students use clickers but have taken steps to prevent this and found no evidence that any cheating occurred. In a larger class, this may be more of an issue.
} 
For both groups, the instructor revisited some of the key concepts based on the percentage of students who missed each quiz question. The instructor was diligent in spending the same amount of time revisiting key concepts for both groups so that the only difference in the quiz review was the timing - either embedded in the lecture for the SRS group or at the beginning of the next class period for the non-SRS group - and not the quality of the quiz review. ${ }^{14}$ For both groups, quiz questions and answers were made available to all students for studying purposes after the quiz was completed and discussed in class.

On the designated final exam date during finals week all participants completed an anonymous post-experimental survey regarding their classroom experiences. To obtain the post-experimental information and debrief the participants, the final exam for the course was administered on the last class date. ${ }^{15}$ Although the final exam had already been completed prior to obtaining the post-experimental information, no scores were released until students had completed the post-experimental survey.

\section{Results}

A total of 86 undergraduate students, enrolled in two principles of accounting classes at a large state university, participated in this study. The SRS group consisted of 38 students and the nonSRS group consisted of 48 students. The same instructor taught both sections. Prior to analyzing the hypotheses, we performed the following steps to validate the data. First, we analyzed student demographics as a means to identify potential outliers. Although we did not identify any outliers, we excluded several observations from data analysis due to participants dropping, missing examinations, and failing to complete part of the post-experimental questionnaire. ${ }^{16}$ The proportion of students dropping was not statistically significant between the two sections. After excluding these observations, we had a total of 60 usable observations, with 28 students in the SRS group and 32 in the non-SRS group. ${ }^{17}$

Demographic information pertaining to the students is shown in Table 1. Female participants represented a slightly smaller portion of the sample $(47 \%, n=28)$ than male $(53 \%, n=32)$. The average student age was $23.62^{18}$ and their GPAs measured at the start of the semester were in the range of 1.70-4.00 (mean $(M)=2.78$ ). There were no significant differences between the two sections with respect to GPA or age. The majority of the participants were born in the US (97\%, $n=58$ ). The SRS group met 2 days a week from 2:00 to 3:30 pm, while the non-SRS group met 2 days a week from 6:00 to 7:30 pm. There were no significant differences in demographic characteristics of interest between these two groups. ${ }^{19}$ All students were business majors. Moreover, all of the students in the SRS group were traditional students, while two of the students in the non-SRS group identified themselves as non-traditional students who had full-time employment during the day. We ran our data analysis with and without these non-traditional students and did not observe any significant differences in our results. Students from both classes responded to a series of teaching-evaluation questions at the end of the semester. There were no significant differences between the two treatment groups for each evaluation question, similar to the findings of Carnaghan and Webb (2007).

\footnotetext{
${ }^{14}$ An interesting opportunity for future research is to investigate whether an instructor would inadvertently spend more time teaching the topics in a course when using an SRS. While care was taken in this experiment for the instructor to treat each group the same, it may be the case that instructors would naturally be encouraged to spend more time on the material when using an SRS; that is, use of an SRS may impact course delivery.

${ }^{15}$ Scores on the final exam for both student groups did not significantly differ from previous introductory courses taught by the instructor.

16 The number of students missing exams, performing poorly, and dropping the course was consistent with the average number of drops for this instructor in the introductory course for previous semesters.

17 These courses are in the typical sequence for obtaining entrance into the College of Business and enrollment size is typical for this university. The school is located in a large city and could be classified as a commuter school with many students not living on campus and attending the university after either attending a community college or working. Small class sizes are emphasized in principles of accounting at this university to encourage better performance.

18 This is the normal age of students at this level for this university and does not significantly differ from previous semesters.

${ }^{19}$ Our demographic characteristics are consistent with those of prior studies and no prior study found a relationship between demographic characteristics and the variables of interest.
} 
Table 1

Descriptive statistics: Sample $(N=60)$.

\begin{tabular}{|c|c|c|c|}
\hline \multicolumn{3}{|c|}{$\begin{array}{l}\text { Number of male participants } \\
\text { Number of female participants } \\
\text { Number of participants born in the US }\end{array}$} & \multirow{2}{*}{$\begin{array}{l}32 \\
28 \\
58 \\
\text { GPA }\end{array}$} \\
\hline & & Age & \\
\hline Mean & & 23.62 & 2.78 \\
\hline Minimum & & 18 & 1.70 \\
\hline Maximum & & 36 & 4.00 \\
\hline Standard deviation & & 3.94 & 0.50 \\
\hline \multirow[t]{2}{*}{ Demographic categories } & \multicolumn{2}{|c|}{ SRS treatment group } & \multirow[t]{2}{*}{ Test statistic ${ }^{\mathrm{a}}(p)$} \\
\hline & SRS group mean & Non-SRS group mean & \\
\hline Male participants & 12 & \multicolumn{2}{|l|}{18} \\
\hline Female participants & 16 & \multicolumn{2}{|l|}{14} \\
\hline Total participants & 28 & \multicolumn{2}{|l|}{32} \\
\hline GPA & 2.75 & 2.80 & $0.229(0.82)$ \\
\hline Age & 22.67 & 24.05 & $1.405(0.17)$ \\
\hline
\end{tabular}

a Chi-square tests were performed on the number of participants test statistics, as the data were categorical. Our Chi-square analysis generated a critical value of 1.07 . The probability of a critical value of 1.07 is greater than 0.10 . Thus, we conclude that there is no statistically significant difference in gender between our two treatment groups. For the remaining demographic information, $t$-tests were performed.

\section{1. $\mathrm{H} 1$}

The dependent variables are students' scores on in-class quizzes, three examinations, and a comprehensive final examination. Students in both the SRS and non-SRS classes had the opportunity to earn 100 in-class quiz points, 300 term examinations points, and 200 comprehensive final examination points during the semester. To test $\mathrm{H} 1$, we performed an independent samples $t$-test on student performance related to the in-class quizzes between the SRS and non-SRS groups. Table 2 presents our $t$-test results. ${ }^{20}$ According to Table 2, participants in the SRS group (mean $(M)=92.25$ ) performed better $(p=0.01)$ than those in the non-SRS group $(M=82.71)$ with regard to the in-class quizzes. This result supports H1. To ensure the results were not driven by a handful of outliers, we performed the same analysis after removing all observations that had average quiz scores less than $60 \%$. This analysis also yielded a significant difference $(t=1.623, p=0.05)$. In addition, we performed a Mann-Whitney test on the median scores from the treatment groups, finding a significant difference $(Z=2.356, p=0.01) .{ }^{21}$

\section{2. $\mathrm{H} 2$}

Our second and third hypotheses predict students with the SRS will be more confident about their comprehension (H2) and, as a result, exert less effort toward the course (H3) than those without it. To test $\mathrm{H} 2$, we compared student expectations for their final grades to their actual course grades earned at the end of the semester. We generated three categories to analyze their performance confidence levels. These categories are (1) below expectation, (2) meet expectation, and (3) above expectation. Below expectation represents the situation when a student's actual course performance is lower than his or her expected grade. Meet expectation is when a student's actual course performance matches with his or her expected grade. Above expectation is when a student's actual course performance exceeds his or her expected grade.

\footnotetext{
${ }^{20}$ We conducted the Levene test for homogeneity of variance. The Levene test result was not significant $(p=0.08)$, indicating failure to reject the null hypothesis of variance homogeneity.

${ }^{21}$ We also used analysis of covariance (ANCOVA) to examine student performance on in-class quizzes by controlling for potential covariates of gender, age, GPA, and attendance. Our ANCOVA results showed that the SRS treatment is significant $(p=0.01)$ after controlling these for the covariates. Thus, the univariate and multivariate results support $\mathrm{H} 1$.
} 
Table 2

Test of H1: Student quiz performance ( $t$-test).

\begin{tabular}{|c|c|c|c|}
\hline \multirow[t]{2}{*}{ Performance category } & \multicolumn{2}{|l|}{ SRS treatment group } & \multirow[t]{2}{*}{$t(p)^{\mathrm{a}}$} \\
\hline & $\begin{array}{l}\text { SRS group }(N=28) \\
\text { Mean }(S D)\end{array}$ & $\begin{array}{l}\text { Non-SRS group }(N=32) \\
\text { Mean }(S D)\end{array}$ & \\
\hline Quizzes (range 0-100) & $92.25(11.25)$ & $82.71(19.13)$ & $2.310(0.01)$ \\
\hline
\end{tabular}

Table 3

Test of H2: Student's confidence (Mann-Whitney test).

\begin{tabular}{|c|c|c|c|}
\hline \multirow[t]{2}{*}{ Expectation categories } & \multicolumn{2}{|l|}{ Mindset treatment group } & \multirow[t]{2}{*}{ Mann-Whitney $(p)^{a}$} \\
\hline & $\begin{array}{l}\text { SRS Group }(N=28) \\
\text { Mean rank/(percentage) }\end{array}$ & $\begin{array}{l}\text { Non-SRS Group }(N=32) \\
\text { Mean rank/(percentage) }\end{array}$ & \\
\hline Below expectation & $34.00(n=14,50.00 \%)$ & $27.44(n=9,28.13 \%)$ & $350.00(0.04)$ \\
\hline Meet expectation & $26.86(n=12,42.86 \%)$ & $33.69(n=21,65.63 \%)$ & $346.00(0.04)$ \\
\hline Above expectation & $30.64(n=2,7.14 \%)$ & $30.38(n=2,6.25 \%)$ & $444.00(0.45)$ \\
\hline
\end{tabular}

${ }^{\text {a }} p$-Values are one-tailed.

We performed the nonparametric Mann-Whitney test on the categorical data. ${ }^{22}$ According to Siegel $(1956,116)$, the Mann-Whitney test is "one of the most powerful of the nonparametric tests, and it is a most useful alternative to the parametric $t$-test." Table 3 presents the results of our Mann-Whitney test results.

Table 3 reports a significant difference in the expectations of SRS and non-SRS students. For the below-expectation category, $50 \%$ of the students in the SRS group over estimated their final course grades, whereas only $28.13 \%$ of the non-SRS group students exhibited over confidence towards their final course grades. ${ }^{23}$ This result suggests that a significant portion of students in the SRS group were overly confident about their performance compared to those in the non-SRS group $(p=0.04)$. Alternatively, students in the non-SRS group were significantly more accurate $(p=0.04)$ about their performance expectations than those in the SRS group, as $65.63 \%$ of students in the non-SRS correctly predicted their final scores compared to only $42.86 \%$ of the students in the SRS group. Thus, H2 is supported in that students in the SRS class were more confident or optimistic about their performances in the class compared to students in the non-SRS class. The better in-class quiz performance by the SRS students may be associated with more optimistic or confident expected outcomes when compared to the non-SRS students.

\section{3. $H 3$}

As stated in H3, we hypothesize that students in the SRS class will exert less effort outside of class towards the course than those without SRS. To test H3, we used an independent samples $t$-test to examine student self-reported times spent on studying for the course. Table 4 presents our results.

Results from Table 4 show a statistically significant between-group difference $(p=0.01)$ in reported time spent on the course. Students in the SRS reported a mean of 7.21 whereas students in the non-SRS group reported a mean of 10.91 , thereby supporting H3. ${ }^{24}$

\footnotetext{
22 Note that treating data as a continuous variable yielded identical results as our non-parametric test.

23 Both treatment groups exhibited some overconfidence toward their course grades. This tendency is consistent with prior research examining grade expectations (Clayson, 2005; Eason et al., 2009; Nowell \& Alston, 2007).

${ }^{24}$ Because the hours of study time were self-reported by the students, we also used students' attendance records as an added independent measure of effort. Specifically, we examined the proportion of classes attended by each student between the class sections, or treatment groups. For the SRS treatment group, average attendance was $82.78 \%$. Conversely, the non-SRS group averaged a daily attendance of $88.22 \%$. We performed a $Z$-test on these percentages to determine whether a significant difference exists. The $p$-value from this $Z$-test was 0.05 . This significant difference lends additional support to the finding that the students in the non-SRS group exerted greater effort towards the course, as demonstrated by class attendance.
} 


\section{Table 4}

Test of H3: Student's effort ( $t$-test).

\begin{tabular}{|c|c|c|c|}
\hline \multirow[t]{2}{*}{ Time spent ${ }^{\mathrm{a}}$} & \multicolumn{2}{|l|}{ SRS treatment group } & \multirow[t]{2}{*}{$t(p)^{\mathrm{b}}$} \\
\hline & $\begin{array}{l}\text { SRS group }(N=28) \\
\text { Mean }(S D)\end{array}$ & $\begin{array}{l}\text { Non-SRS group }(N=32) \\
\text { Mean }(S D)\end{array}$ & \\
\hline Hours (per week) & $7.21(6.08)$ & $10.91(5.58)$ & $2.452(0.01)$ \\
\hline
\end{tabular}

\section{Table 5}

Test of H4: Student's overall course performance ( $t$-test).

\begin{tabular}{|c|c|c|c|}
\hline \multirow[t]{2}{*}{ Performance category $^{\mathrm{a}}$} & \multicolumn{2}{|l|}{ SRS treatment group } & \multirow[t]{2}{*}{$t(p)^{\mathrm{b}}$} \\
\hline & $\begin{array}{l}\text { SRS group }(N=28) \\
\text { Mean }(\mathrm{SD})\end{array}$ & $\begin{array}{l}\text { Non-SRS group }(N=32) \\
\text { Mean }(\mathrm{SD})\end{array}$ & \\
\hline Total course points (range $0-600$ ) & $419.40(59.822)$ & $405.97(73.02)$ & $0.817(0.41)$ \\
\hline
\end{tabular}

\section{4. $\mathrm{H4}$}

Finally, we investigated in $\mathrm{H} 4$ whether overall course performance differs between the groups. Using an independent samples $t$-test, we compared overall course performance based on total points. This analysis is presented in Table 5 . As already analyzed in $\mathrm{H} 1$, in-class quiz performance was significantly better for those with the SRS technology.

The results in Table 5 indicate no significant difference in course performance (total points) between the treatment groups, including the any difference in examination performance for any of the exams. ${ }^{25}$ Thus, overall course performance was no different between the treatments. ${ }^{26}$

\subsection{Supplemental analysis}

In addition to our main test of hypotheses, we conducted supplemental analysis to examine student perceptions of the usefulness of using clickers in the classroom. Prior clicker research, across all disciplines, attempts to evaluate students' perceived benefits of using the SRS. To be consistent with the prior literature and to be able to compare our results with the extant literature, we examined students' perceived benefits from using the SRS technology, both in the treatment and control groups. The perception questions between treatment groups are presented in the Appendix. Responses came from a 7-point Likert-type scale with the endpoints of $1=$ "strongly disagree" and 7 = "strongly agree." The questions were asked at the end of the semester in a post-experiment questionnaire. Those in the SRS group responded based on their experience using the technology during the semester. Conversely, those in the non-SRS group were shown the SRS technology and asked to predict how beneficial the

\footnotetext{
${ }^{25}$ We also compared total course points from the treatment groups to the performance of students in the instructor's previous three introductory accounting courses, which were run in a similar manner other than the inclusion of a clicker system. We note that the overall course performance from our test groups did not significantly differ from the prior introductory courses.

${ }^{26}$ We also used analysis of covariance (ANCOVA) to examine course performance by controlling for potential covariates of gender, age, GPA, and attendance. Our ANCOVA results showed that the SRS treatment is insignificant $(p=0.52)$ after controlling these for the covariates. Thus, the univariate and multivariate results both support $\mathrm{H} 4$.
} 
technology would be to them in the classroom. ${ }^{27}$ Consistent with the prior literature, those in the SRS group perceived the technology to be more beneficial to the class and to their course performance compared to students in the control group. However, as noted above, this perceived benefit did not translate into better course performance.

\section{Discussion and conclusions}

This paper further examines the influence of the SRS in introductory accounting courses. The technology offers a unique opportunity for instructors to provide instantaneous feedback about comprehension to themselves and the students. Despite the perceived benefits, prior studies both within and outside of accounting have found conflicting results as to whether the SRS translates into better course performance (Caldwell, 2007; Kay \& LeSage, 2009; MacArthur \& Jones, 2008). Through using an experimental design with a high degree of control, we compared and contrasted the clickers with the most common alternative form of feedback available to educators, periodic quizzes with delayed feedback. Moreover, we assessed the influence of clickers on the individual characteristics of confidence and effort.

We found the students with clickers performed better on in-class quizzes than their counterparts who took traditional quizzes at the end of the class period. In addition, the students in the SRS group were more confident in their estimation of their final grade and reported less time spent studying than the students in the non-SRS group. Despite the differences in quiz performance and reported individual characteristics, overall course performance did not differ based on whether a clicker was made available to the student during the semester.

Our study is subject to the following limitations. First, we are only focusing on students enrolled in a lower level accounting course. Students who enroll in an upper level accounting course may perform differently with SRS. The use of SRS in upper level accounting courses is an area that we feel is important in future research as it has not been explored thus far. Second, the class time was different for the two quasi-experimental groups; one section was a day section, and the other a night section. However, we did not find any demographic differences between the day and night sections (including GPA and age). Additionally, both classes met twice a week and the difference in class time was minimal as the afternoon class was from 2:00 to 3:30 pm and the evening class was from 6:00 to 7:30 pm. Another limitation is the measurement of confidence, an item difficult to measure given that it is a latent variable. Nevertheless, we tried to guard against students misreporting their levels of confidence in their abilities by obtaining their anticipated performance in the course, whereby overconfident individuals would expect to receive a higher grade than what they actually earned. Although there is a possibility that our metric does not fully capture the confidence levels of students, the relationship between study time and confidence found in our study is significant enough to support the proposition that confidence was appropriately captured. Next, the out of class study hours were self-reported by the students and therefore have the possibility to be inaccurate. Nevertheless, the difference in class attendance between the treatment groups provides additional support that the non-SRS group exerted more effort towards the course. Finally, in the supplemental analysis of the perceived benefits of using SRS technology, those in the control group were asked to predict the benefits of the technology based on very limited exposure. We included such a questionnaire since these questions were analyzed in prior SRS studies and we attempted to reconcile our study with those of prior findings.

The results of our study lay the foundation for additional future research. First, future research could investigate ways to exploit the benefits (i.e., improving student in-class quiz performance) gained by using SRS in the classroom, while mitigating the effects of overconfidence and reduced efforts from students (which appears to make the overall effect of SRS on course performance null). If the negative effects could somehow be mitigated, we believe that SRS could contribute to an increase in student course performance in the context of in-class quizzes as well as student effort.

\footnotetext{
27 The authors note that the perceived usefulness of the non-SRS group is only based on 10-15 min of demonstration on how the clickers work and a few example questions. Thus, the students' exposure was limited. However, our evaluation of the perceived benefit of SRS is consistent with that of prior literature.
} 
Researchers could also further investigate how an SRS may impact other areas of student learning. Learning is a complex and multifaceted construct. This study focused exclusively on course performance (which is defined as the scores attained by students during in-class activities such as quizzes and exams). However, there are other elements of learning that may be affected by SRS; nevertheless, researchers will need to carefully define what aspect of learning they are investigating before establishing any links to the use of SRS. Defining the specific aspect of learning would help researchers avoid potential pitfalls in crediting or discrediting the influence of SRS on student learning. For instance, there is a difference between assessments for learning and assessment of learning. Although we found evidence to suggest that SRS improves student in-class quizzes performance, due to the limited scope of our study, we have not examined whether deep and permanent learning has occurred. Thus, researchers can further investigate how SRS may influence deep and permanent learning. Specifically, education research has shown that studying strategies have the potential to either enhance or lessen deep/surface learning as well as influence the development of generic and discipline-specific skills (Booth, Luckett, \& Mladenovic, 1999; Boyce, Williams, Kelly, \& Yee, 2000). It would be a fruitful endeavor for researchers to investigate how the use of SRS in conjunction with various learning strategies may influence different kinds of learning. Does the use of SRS only prompt surface learning or does it influence deep and permanent learning? Does the use of SRS mediate or moderate course performance in conjunction with different learning strategies? These type questions may warrant further investigation.

Feedback in general is considered a critical component to most educational learning models and theories (Bangert-Drowns et al., 1991). One of the major components of feedback that has received considerable attention and debate is the timing of feedback. Immediate feedback is generally more effective than delayed feedback. However, we found the benefit of the immediate SRS feedback was temporary as quiz performance improved but overall performance remained unchanged. Some feedback research indicates that the delivery option of the feedback and the task significantly influence the effectiveness of feedback (Mory, 1996). Future research could examine how the type of knowledge to be acquired in an accounting course interacts with the delivery option of clickers and its influence on student learning.

Finally, future research could explore how using SRS might affect the manner in which instructors teach. In this quasi-experiment, care was taken for the instructor to treat both groups similar in all ways other than the SRS technology. However, in a natural context, using the SRS technology may influence the way an instructor conducts his or her class. For example, it may be the case that instructors are encouraged to spend more total time discussing topics when using SRS, which may also influence student course performance. We would encourage researchers to consider our quasiexperimental design in future study related to the use of SRS. The use of a control group (with no SRS) in the same academic semester provides a higher degree of experimental control. It also helps researchers to more meaningfully interpret the results of their study.

SRSs are becoming more popular as alternate methods of implementing them are introduced (e.g., smart phones, laptops, and traditional purchased "clickers"). However, accounting educators should be aware of the increased artificial sense of confidence that may stem from using SRSs, which could reduce overall effort and time spent studying by students. Furthermore, we did not find that the SRS either improved or decreased overall student course performance. We suggest further research be done on the benefits of SRS prior to implementing in our classrooms. SRS offers many benefits to educators such as providing instant feedback to both the instructors and the students. However, there are still many unanswered questions as to how SRS influences the many aspects of student learning.

\section{Acknowledgements}

This research project has benefited from helpful comments from the participants at the 2010 American Accounting Association Midwest Region Annual Meeting. In addition, the authors greatly appreciate the insightful comments and suggestions provided by our two anonymous reviewers, the associate editor, as well as David E. Stout, editor-in-chief of the Journal of Accounting Education. 


\section{Appendix. Supplemental analysis}

Questions on student perception of the usefulness of SRS

\begin{tabular}{|c|c|c|}
\hline & SRS group & Non-SRS group \\
\hline Q1 & $\begin{array}{l}\text { I enjoyed using the student response device } \\
\text { (clicker) in class. }\end{array}$ & $\begin{array}{l}\text { I think I will enjoy using the student } \\
\text { response device (clicker) in my class. }\end{array}$ \\
\hline Q2 & $\begin{array}{l}\text { The student response device (clicker) } \\
\text { allowed me to better comprehend the course } \\
\text { material. }\end{array}$ & $\begin{array}{l}\text { I think using the student response device } \\
\text { (clicker) will allow me to better comprehend } \\
\text { the course material. }\end{array}$ \\
\hline Q3 & $\begin{array}{l}\text { The student response device (clicker) } \\
\text { provided me with instant feedback on how } \\
\text { well I comprehended the course material. }\end{array}$ & $\begin{array}{l}\text { I think using the student response device } \\
\text { (clicker) will provide me with instant } \\
\text { feedback on how well I comprehend the } \\
\text { course material. }\end{array}$ \\
\hline Q4 & $\begin{array}{l}\text { The student response device (clicker) } \\
\text { improved my understanding and helped me } \\
\text { perform better on my exams. }\end{array}$ & $\begin{array}{l}\text { I think using the student response device } \\
\text { (clicker) will improve my understanding and } \\
\text { helps me perform better on my exams. }\end{array}$ \\
\hline Q5 & $\begin{array}{l}\text { The student response device (clicker) } \\
\text { improved my overall learning experience in } \\
\text { the classroom. }\end{array}$ & $\begin{array}{l}\text { I think using the student response device } \\
\text { (clicker) will improve my overall learning } \\
\text { experience in the classroom. }\end{array}$ \\
\hline Q6 & $\begin{array}{l}\text { I will recommend other instructors use the } \\
\text { student response devices (clickers) in their } \\
\text { classes. }\end{array}$ & $\begin{array}{l}\text { I would like other instructors to use the } \\
\text { student response devices (clickers) in their } \\
\text { classes. }\end{array}$ \\
\hline Q7 & $\begin{array}{l}\text { I liked using the student response device } \\
\text { (clicker). }\end{array}$ & $\begin{array}{l}\text { I think I will like using the student response } \\
\text { device (clicker). }\end{array}$ \\
\hline
\end{tabular}

\section{References}

Ammons, J. L., \& Mills, S. K. (2005). Course-embedded assessments for evaluating cross-functional integration and improving the teaching-learning process. Issues in Accounting Education, 20(1), 1-19.

Angelo, T. A. (1991). Introduction and overview: From classroom assessment to classroom research. New Directions for Teaching and Learning, 46, 7-15.

Angelo, T. A., \& Cross, K. P. (1993). Classroom assessment techniques: A handbook for college teachers (2nd ed.). San Francisco: Jossey-Bass Publishers.

Bangert-Drowns, R. L., Kulik, C. C., Kulik, J. A., \& Morgan, M. T. (1991). The effects of frequent classroom testing. The Journal of Educational Research, 85(2), 89-99.

Bell, J. D. (2003). State higher education: Is it measuring up? National Conference of State Legislatures.

Bojinova, E. D., \& Oigara, J. N. (2011). Teaching and learning with clickers: Are clickers good for students? Interdisciplinary Journal of E-Learning and Learning Objects, 7, 169-183.

Bonwell, C. C., \& Eison, J. A. (1991). Active learning: Creating excitement in the classroom. ASHEERIC higher education report no. 1. Washington, DC: The George Washington University.

Booth, P., Luckett, P., \& Mladenovic, R. (1999). The quality of learning in accounting education: The impact of approaches to learning on academic performance. Accounting Education, 8(4), 277-300.

Boyce, G., Williams, S., Kelly, A., \& Yee, H. (2000). Fostering deep and elaborative learning and generic (soft) skill development: The strategic use of case studies in accounting education. Accounting Education, 10(1), 37-60.

Brown, G., Bull, J., \& Pendlebury, M. (1997). Assessing student learning in higher education. New York: Routledge.

Caldwell, J. E. (2007). Clickers in the large classroom: Current research and best-practice tips. Life Sciences Education, 6(1), 9-20.

Carnaghan, C., \& Webb, A. (2007). Investigating the effects of group response systems on student satisfaction, learning, and engagement in accounting education. Issues in Accounting Education, 22(3), 391-409.

Clayson, D. E. (2005). Performance overconfidence: Metacognitive effects or misplaced student expectations? Journal of Marketing Education, 27(2), 122-129.

Cottell, P. G. Jr., (1991). Classroom research in accounting: Assessing for learning. New Directions for Teaching and Learning, 46, 43-54. 
Cottell, P. G., Jr., \& Harwood, E. M. (1998). Using classroom assessment techniques to improve student learning in accounting classes. Issues in Accounting Education, 13(3), 551-564.

Eason, J. F., Marcis, J. G., Burney, R. B., \& Boyles, G. V. (2009). Grade expectations: Evidence of cognitive biases in students academic self-assessment in the introductory finance course. American Society of Business and Behavioral Sciences, 1(16), 1-17.

Edmonds, C. T., \& Edmonds, T. P. (2008). An empirical investigation of the effects of SRS technology on introductory managerial accounting students. Issues in Accounting Education, 23(3), 421-434.

Eisenbach, R., Golich, V., \& Curry, R. (1998). Classroom assessment across the disciplines. New Directions for Teaching and, Learning 75.

Fies, C., \& Marshall, J. (2006). Classroom response systems: A review of the literature. Journal of Science Education and Technology, 15(1), 101-109.

Fogarty, T. J., \& Goldwater, P. M. (2010). Beyond just desserts: The gender nature of the connection between effort and achievement for accounting students. Journal of Accounting Education, 28, 1-12.

Grygoryev, K., \& Karapetrovic, S. (2005). An integrated system for educational performance measurement, modeling and management at the classroom level. The TQM Magazine, 17(2), 121.

Halabi, A. K., Touvinen, J. E., \& Farley, A. A. (2005). Empirical evidence on the relative efficiency of worked examples versus problem-solving exercises in accounting principles instruction. Issues in Accounting Education, 20(1), 21-32.

Horsburgh, M. (1999). Quality monitoring in higher education: The impact on student learning. Quality in Higher Education, 5(1).

Kay, R. H., \& LeSage, A. (2009). Examining the benefits and challenges of using audience response systems: A review of the literature. Computers and Education, 53, 819-827.

Kirk, R. E. (1968). Experimental design: Procedures for the social sciences. Belmont, CA: Wadsworth.

MacArthur, J. R., \& Jones, L. L. (2008). A review of literature reports of clickers applicable to college chemistry classrooms. Chemistry Education Research and Practice, 9, 187-195.

Mory, E. H. (1996). Feedback research. In D. H. Jonassen (Ed.), Handbook of research for educational communication and technology. New York: Simon and Schuster Macmillan.

Mory, E. H. (2003). Feedback research revisited. In D. H. Jonassen (Ed.), Handbook of research for educational communication and technology: A project of the association for educational communications and technology (2nd ed.. Mahway, NJ: Lawrence Erlbaum.

Mula, J. M., \& Kavanagh, M. (2009). Click go the students, click-click-click: The efficacy of a student response system for engaging students to improve feedback and performance. E-Journal of Business Education and Scholarship Teaching, 3(1), $1-17$.

Nowell, C., \& Alston, R. M. (2007). I thought I got an A! Overconfidence across the economics curriculum. Journal of Economic Education, 38(2), 131-142.

Parry, R. W. (1990). The impact of assigned study groups on study effort and examination performance. Issues in Accounting Education, 5(2), 222-239.

Renner, C. H., \& Renner, M. J. (2001). But I thought I knew that: Using confidence estimation as a debiasing technique to improve classroom performance. Applied Cognitive Psychology, 15, 23-32.

Segovia, J. (2008). Personal response system and its effect on student learning. Accounting Instructors' Report (Winter).

Siegel, S. (1956). Nonparametric statistics for the behavioral sciences. New York, NY: McGraw-Hill Book Company, Inc.

Webb, J. M., Stock, W. A., \& McCarthy, M. T. (1994). The effects of feedback timing on learning facts: The role of response confidence. Contemporary Educational Psychology, 19, 251-265. 